\title{
In vitro Antidiabetic, anti-obesity and antioxidant proprities of Rosemary extracts
}

\author{
Manel Ben Ali ${ }^{1}$, Kais Mnafgui ${ }^{2}$, Abdelfattah Feki ${ }^{2}$, Mohamed Damak ${ }^{1}$ and \\ Noureddine Allouche ${ }^{1^{*}}$ \\ ${ }^{1)}$ Laboratory of chemistry of natural substances, University of Sfax, Faculty of Sciences of Sfax, 3000, P.B. \\ "1171", Sfax, Tunisia. \\ ${ }^{2)}$ Laboratory of Animal Ecophysiology, University of Sfax, Faculty of Sciences of Sfax, 3052, P.B. "95”, Sfax, \\ Tunisia. \\ *noureddineallouche@yahoo.fr (Corresponding author)
}

\begin{abstract}
Diabetes mellitus is a serious health problem worldwide that has adverse and long-lasting consequences for individuals, families, and communities. Hence, this study sought to investigate the inhibitory potential of rosemary extracts on keyenzymes related to diabetes such as a-amylase and pancreatic lipase activities, as well as to assess their antioxidant properties in vitro. The $\mathrm{IC}_{50}$ values of Rosemary essential oil, ethyl acetate and methanolic extracts against $\alpha$-amylase were 28.36, 34.11 and $30.39 \mu \mathrm{g} / \mathrm{mL}$ respectively, and those against pancreatic lipase were $32.25,36.64 \mathrm{and} 34.07 \mu \mathrm{g} / \mathrm{mL}$, suggesting strong anti-diabetic and anti-obesity effects of Rosemary. The methanolic extract was found to be the highest in levels of phenolic (282.98 $\mu \mathrm{gGAE} / \mathrm{mg}$ extract) and flavonoids (161.05 $\mu \mathrm{g} \mathrm{QE} / \mathrm{mg}$ extract) contents as well as in the antioxidant activity $\left(\mathrm{IC}_{50}=15.82 \mu \mathrm{g} / \mathrm{mL}\right)$ as compared to other extracts ethyl acetate $\left(\mathrm{IC}_{50}=32.23 \mu \mathrm{g} / \mathrm{mL}\right)$ and essential oil $\left(\mathrm{IC}_{50}=96.12 \mu \mathrm{g} / \mathrm{mL}\right)$.

Antioxidant efficacy of Rosemary extracts has been estimated in the stabilization of sunflower oil (SFO) at three different concentrations, i.e. 200 (SFO-200), 500 (SFO-500) and 1000 ppm (SFO-1000). Results showed the highest efficiency of SFO-1000.

The results obtained in this study demonstrated for the first time that Rosemary is a potent source of natural inhibitors of a-amylase and pancreatic lipase with powerful antioxidants proprieties that might be used in the food stabilization and the prevention of diabetes and obesity complications as a complementary pharmacological drug.
\end{abstract}

\section{Keywords}

Rosemary; diabetes; $\alpha$-amylase; lipase; essential oil; oil stabilization

\section{Academic Discipline And Sub-Disciplines}

Chemistry

\section{SUBJECT CLASSIFICATION}

Plant extracts with antioxidant, antiobesity and antidiabetic activties

\section{TYPE (METHOD/APPROACH)}

Experimental

\section{Council for Innovative Research}

Peer Review Research Publishing System

Journal: Journal of Advances in Chemistry

Vol. 10, No. 2

editorjaconline@gmail.com

www.cirjac.com 


\section{INTRODUCTION}

Diabetes mellitus is a chronic disorder and considered as a major risk for developing several medical complications, including coronary vascular diseases and dyslipidemia [1]. One of the therapeutic approaches to treat the diabetes is to decrease the postprandial hyperglycemia by retarding absorption of glucose. Inhibition of carbohydrate-hydrolyzing enzymes, such as a-amylase, is considered a possible pathway because the enzyme plays a key role in digesting carbohydrates [2]. On the other side, diabetes mellitus is well known by higher risk association with hyperlipidemia [3]. In fact, pancreatic lipase is secreted from the pancreas and hydrolyzes non-absorbable triglycerides (TG) into absorbable glycerol and fatty acids by small intestine [4]. Thus, pancreatic lipase inhibitors may reduce postprandial plasma lipids level through delaying TG hydrolysis in the gastrointestinal tract and therefore, free fatty acids absorption. Hence, pancreatic lipase inhibitors are considered to be a valuable therapeutic tool for management of hyperlipidemia in humans [5]. Moreover, oxidative stress is highly correlated with a wide variety of inflammatory and metabolic disease states, including diabetes. Indeed, the increase of reactive oxygen species (ROS) leads to damage of $\beta$-cells through the induction of apoptosis and suppression of insulin biosynthesis [6]. On the other hand, Lipid peroxidation is responsible for the quality deterioration of vegetable oils, fats and other food systems [7]. It lowers the nutritive value of food and deteriorates its flavour and taste [8]. It also causes aging, heart diseases, stoke, emphysema, mutagenesis and carcinogenesis [9]. The oil industry has to pay special attention in this context, as oils, fats and fatty foods suffer stability problems. Oil manufacturers aim at producing foods that maintain their shelf life and nutritional quality over a defined period. Thus, the use of antioxidants to minimize the oxidation of lipids in food materials is extensively practised.

In today's consumer perception of agriculture and food production, aspects like health, safety and quality have become the key words. In these circumstances, research on development of safer natural antioxidants is the need of hour. Plant extracts provide phenolic antioxidants that might exhibit strong activity. Subjects of investigation have been various spice, herb and olive mill waste extracts, as well as fruits and vegetables $[10,11,12]$. In a previous study, we have used the polyphenolic extract from olive mill waste water and basil extract for the stabilization of refined oils [13,14].

Among natural herbs, rosemary has been widely accepted as one of the species with the highest antioxidant activity [15]. Rosemary (Rosmarinus officinalis L., Lamiaceae) is an aromatic, evergreen, shrubby herb indigenous to most countries bordering on the Mediterranean sea, which is widely used in pharmaceutical products and folk medicine [16]. In Tunisia, it is traditionally used for the treatment of auricular diseases, liver diseases, asthma, dermatoses, bronchitis, cough, asthenia, gastralgia, otitis and cold. Rosemary bears linear, leathery dark green, needle like leaves and light, sky blue flowers. When dried, the leaves become rolled in appearance and dark green to brownish green in color [17].

The purpose of this work is to assess the inhibitory potential of Rosemary extracts against $\alpha$-amylase and pancreatic lipase in vitro and to estimate the stabilizing efficiency of these extracts against oxidative deterioration. Refined, bleached and deodorized (RBD) sunflower oil was chosen to evaluate the antioxidant efficiency of rosemary extracts, because of its wide use among Tunisian population and due to its higher content of polyunsaturated fatty acids. Furthermore, the stabilization effect is more pronounced in sunflower oil [18].

\section{EXPERIMENTAL}

\section{Materials}

Sample of refined-bleached-deodorized (RBD) sunflower oil (SFO), without additives was received from a local commercial refining plant (Agrimed, Sfax). Fresh rosemary (Rosmarinus officinalis L.) leaves were harvested from Sfax province in the center of Tunisia in October 2012. All the chemicals and reagents used were of analytical reagent grade and were purchased from Fluka, or Sigma Chemical Co (St. Louis, MO, USA).

\section{Solvent Extraction}

Dried rosemary leaves $(500 \mathrm{~g})$ were chopped and extracted with organic solvents of increasing polarity: ethyl acetate and methanol. The extraction procedure is reported in our previous study [14 ]

\section{Extraction of essential oil}

The fresh aerial part of rosemary was completely immersed in water and hydro-distilled for 4 hours in a Clevenger-type apparatus giving greenish-yellow oil. The essential oil was taken up in diethyl ether, dried over anhydrous sodium sulphate and stored in a dark glass bottle at $4{ }^{\circ} \mathrm{C}$ until tested and analyzed. The extraction yield was $0.83 \%(\mathrm{w} / \mathrm{w})$.

\section{Liquid chromatography-mass spectrometry (LC-MS)}

Electrospray ionisation mass spectroscopic (ESleMS) analysis of phenolic compounds in $\mathrm{MeOH}$ was performed using an Applied Biosystems (LC/MSD TRAP _ CT) using the separation module (Knawer Analogy). Compounds were separated on C18 column (Zorbax, $2.6 ; 250 \mathrm{~mm}, 3.5 \mathrm{~mm}$ particle size) and a diode array detector (DAD) using a gradient system consisting of solvent $A$ (water, $0.1 \%$ formic acid) and solvent B (Acetonitrile, $0.1 \%$ formic acid). Column temperature was maintained at $25{ }^{\circ} \mathrm{C}$. A stepwise gradient system started from $90 \% \mathrm{~A}$ at $1 \mathrm{~min}$, to $20 \% \mathrm{~B}$ at $4 \mathrm{~min}, 80 \% \mathrm{~B}$ at $30 \mathrm{~min}, 100 \%$ $\mathrm{B}$ at $32 \mathrm{~min}, 100 \% \mathrm{~B}$ at $36 \mathrm{~min}$ and $20 \% \mathrm{~B}$ at $38 \mathrm{~min}$ was applied at a flow rate of $500 \mu \mathrm{l} / \mathrm{min} 6 \mathrm{~min}$. Electrospray mass spectra data were recorded on a negative ionisation mode for a mass range $50 \mathrm{~m} / \mathrm{z}$ to $1000 \mathrm{~m} / \mathrm{z}$. Mass spectra were achieved by electrospray ionisation in negative mode. Capillary voltage was set at $4500 \mathrm{v}$. The electrospray probe-flow was adjusted to $8 \mathrm{ml} / \mathrm{min}$. Identification of the phenolic compounds was achieved by comparison with ESleMS spectra comparisons with literature reports. 


\section{Determination of total flavonoid concentration}

The content of total flavonoid was determined by colorimetric assays using the $\mathrm{AlCl}_{3}$ method of Lamaison and Carnat [19] as described by Khadri et al. [20]. Briefly, $1 \mathrm{ml}$ of extract solution was added to $1 \mathrm{ml}$ of $2 \%$ aluminium trichloride $\left(\mathrm{AlCl}_{3}\right)$ methanolic solution. The absorbance was measured 10 min later at $415 \mathrm{~nm}$. The total flavonoid content was calculated by a standard quercetin graph (treated in the same conditions) and the results expressed in $\mu \mathrm{g}$ of quercetin equivalents per $\mathrm{mg}$ of dry weight of extract. The assay was performed in triplicate for each extract.

\section{Determination of total phenolic concentration}

Total phenolic contents were assayed using the Folin-Ciocalteu reagent, following Singleton's method slightly modified by Oktay et al. [21] and gallic acid as a standard. The total phenolic content was calculated by a standard gallic acid graph, and the results expressed in $\mu \mathrm{g}$ of gallic acid equivalents per $\mathrm{mg}$ of dry weight of extract. The assay was performed in triplicate for each extract [14].

\section{Determination of $\alpha$-amylase activity in vitro}

The in vitro $\alpha$-amylase inhibition activity of all extracts was determined based on the spectrophotometric assay using acarbose as the reference compound [22]. The plant extract was dissolved in DMSO to give concentrations from 25, 50 and $100 \mu \mathrm{g} / \mathrm{ml}$. The enzyme $\alpha$-amylase solution was prepared by mixing $3.246 \mathrm{mg}$ of $\alpha$-amylase in $100 \mathrm{ml}$ of $40 \mathrm{mM}$ phosphate buffer, $\mathrm{pH}$ 6.9. Positive control, acarbose was obtained by dissolving $50 \mathrm{mg}$ in $50 \mathrm{ml}$ of phosphate buffer and diluted to get concentrations of 25,50 and $100 \mu \mathrm{g} / \mathrm{ml}$. The essays were conducted by mixing $80 \mu \mathrm{l}$ of plant extract, $20 \mu \mathrm{l}$ of $\alpha$-amylase solution and $1 \mathrm{ml}$ of 2 -chloro-4-nitrophenol- $\alpha$-D-maltotrioside (CNPG3). The mixture was incubated at $37^{\circ} \mathrm{C}$ for 5 minutes. The absorbance was measured at $405 \mathrm{~nm}$. Similarly, a control reaction was carried out without the plant extract/acarbose. Percentage inhibition (PI) was calculated by the expression:

$$
P I=\frac{\text { Absorbanc }_{\text {ontrol }}-\text { Absorbancest }_{\text {lest }}}{\text { Absorbance entrol }} \times 100
$$

\section{Pancreatic lipase in vitro assay}

The method was modified from the assay reported by Nakai et al. [23], in which 4-methylumbelliferyl oleate (4-MU oleate) was used as a substrate to measure the pancreatic lipase inhibitory activity of all samples. Briefly, the assay was conducted by mixing $50 \mu \mathrm{L}$ of the pancreatic lipase solution $(2 \mathrm{unit} / \mathrm{ml}$ ) in a buffer consisting of $50 \mathrm{mmol} / \mathrm{L} \mathrm{Tris} \mathrm{HCl}(\mathrm{pH}$ 8.0), $100 \mu \mathrm{L}$ of diluted sample solutions and $50 \mu \mathrm{L}$ of $0.5 \mathrm{mmol} / \mathrm{L} 4-\mathrm{MU}$ solution dissolved in the above buffer in the well of a 96 micro well plate to start the enzyme reaction. The plate was immediately placed in the $37^{\circ} \mathrm{C}$ pre-heating $\mathrm{FL} \times 800$ micro plate fluorescence reader (Bio-Tek ${ }^{\circledR}$ Instruments, Inc., Winooski, VT) to measure the amount of 4methylumbelliferone released by lipase every minute for $30 \mathrm{~min}$ at an excitation wavelength of $360 \mathrm{~nm}$ with a tolerance of $\pm 40 \mathrm{~nm}$ and an emission wavelength of $455 \mathrm{~nm}$ with a tolerance of $\pm 20 \mathrm{~nm}$. The lipase inhibitive activity was determined by measuring the effect on the enzyme reaction rate after adding extracts, compared with the control. Fluvastatin was used as positive control.

\section{DPPH radical scavenging assay}

Determination of antioxidant activity of rosemary extracts and essential oil was accomplished using the 1,1-diphenyl-2picrylhydrazyl (DPPH radical) scavenging method as employed by Fki et al. [13] using a Shimadzu UV-160A spectrophotometer, BHT was employed as reference [14 ].The antioxidant activity of each test sample and BHT was expressed in terms of concentration required to inhibit $50 \% \mathrm{DPPH}$ radical formation $\left(\mathrm{IC}_{50} \mu \mathrm{g} / \mathrm{ml}\right)$ and calculated from the log-dose inhibition curve.

\section{Gas chromatography-mass spectrometry (GC-MS)}

The analysis of the essential oil was performed on a GC-MS HP model 5975B inert MSD (Agilent Technologies, J\&W Scientific Products, Palo Alto, CA, USA), equipped with an Agilent Technologies capillary DB-5MS column (30 m length; $0.25 \mathrm{~mm}$ i.d.; $0.25 \mathrm{~mm}$ film thickness), and coupled to a mass selective detector (MSD5975B, ionization voltage $70 \mathrm{eV}$; all Agilent, Santa Clara, CA). The carrier gas was $\mathrm{He}$ and was used at $1 \mathrm{ml} \mathrm{min}^{-1}$ flow rate. The oven temperature program was as follows: $1 \mathrm{~min}$ at $100{ }^{\circ} \mathrm{C}$ ramped from 100 to $260^{\circ} \mathrm{C}$ at $4^{\circ} \mathrm{C} \mathrm{min}{ }^{-1}$ and $10 \mathrm{~min}$ at $260{ }^{\circ} \mathrm{C}$. The chromatograph was equipped with a split/splitless injector used in the split mode. The split ratio was 1:100. Identification of components was assigned by matching their mass spectra with Wiley and NIST library data, standards of the main components and comparing their Kovats Retention Indices (KRI) with reference libraries [24, 25] and from the literature. The component concentration was obtained by semi-quantification by peak area integration from GC peaks and by applying the correction factors. 


\section{Evaluation of thermal stability}

Methanolic extract, exhibiting the powerful antioxidant activity, was used for further studies. Thermal stability of rosemary methanolic extract was evaluated by heating at $185^{\circ} \mathrm{C}$ in an oven for a period of $120 \mathrm{~min}$ in separate crucibles. After each interval, a crucible was removed from the oven, cooled to room temperature and used for antioxidant activity determination following the DPPH radical scavenging assay.

\section{Sample preparation for oxidative stability determination}

The rosemary methanolic extract (RME) was applied to preheated RBD sunflower oil at different concentrations (200, 500 and $1000 \mathrm{ppm}$, based on extract weight), in a series of dark brown coloured bottles to examine its antioxidative activity. Synthetic antioxidant (BHT) was employed at its legal limit of 200 ppm [26]. The antioxidant enriched oil samples were evaporated in a vacuum evaporator below $40^{\circ} \mathrm{C}$ to evaporate the solvent and then subjected to Rancimat assay for oil oxidation evaluation.

\section{Evaluation of oil oxidation by the rancimat}

Induction time to primary oxidation of lipid in sunflower oil was measured using a Rancimat apparatus (Metrohm, Herisau, Switzerland)]. Induction period (IP), the time elapsed from the beginning until the oil starts to become rancid, was measured by drawing tangents on both sides of the induction curve, the intercept of which meet the time axis.

\section{Weight gain analysis}

Analysis procedure is the same adopted in our previous study [14]. For weight gain analyses, $2.0 \mathrm{~g}$ of each sample (in triplicate) were placed in glass Petri dishes, which were kept in a vacuum oven overnight at $35^{\circ} \mathrm{C}$ to remove any traces of moisture. The samples were reweighed and stored in the oven at $70^{\circ} \mathrm{C}$, along with other samples. The rate of oxidation, in terms of weight increase, was recorded at $24 \mathrm{~h}$ intervals up to 16 days. The time required for a $0.5 \%$ weight increase for oil was taken as the index of stability.

\section{Statistical analysis}

All analyses were performed in triplicate and data were reported as means \pm standard deviation (SD). Differences between experiments were analyzed using Student's t-test in Microsoft Excel 2000 (Microsoft Corporation, USA). The confidence limits used in this study were based on $95 \%(P<0.05)$.

\section{RESULTS AND DISCUSSION}

\section{Extraction and antioxidant activity determination}

Table 1 shows the percentage yield and antioxidant activity of rosemary extracts in different solvents as well as its essential oil. Range of extracts yields was $0.83-25.15 \%$. It has been established that the extraction yield increases with increasing polarity of the extracting solvent [12]. In this study, highest yield was not obtained in methanol but in ethy acetate extract and lowest is related to the essential oil. Hence rosemary is rich with medium polarity coumpounds,

Table 1 indicates that all rosmary extracts exhibited antiradical activity . Methanolic extract (IC50 $=15.82 \mu \mathrm{g} / \mathrm{ml})$ is $\mathrm{more}$ active than BHT $\left(I_{50}=25,62 \mu \mathrm{g} / \mathrm{ml}\right)$. Therefore, this extract was used for the stabilization of sunflower oil.

Table 1: Percentage yield and antioxidant activity of rosemary extracts

\begin{tabular}{|c|c|c|}
\hline Sample & Yield (\%) & IC50 $(\boldsymbol{\mu g} / \mathbf{m l})$ \\
\hline Ethyl acetate extract & $25.15 \pm 0.26$ & $15.82 \pm 0.10$ \\
\hline Methanolic extract & $5.22 \pm 0.28$ & $96.12 \pm 0.05$ \\
\hline Essential oil & $0.83 \pm 0.04$ & $25.62 \pm 0.06$ \\
\hline BHT & - & \\
\hline
\end{tabular}

Data are mean $(n=3) \pm$ standard deviation $(n=3),(p<0.05)$.

nd : not determined

\section{GC/MS analysis}

The chemical composition of Rosmarinus officinalis $L$. essential oil is presented in Table 2. The average yield in essential oil was $0.96 \%(w / w)$. GC-MS analysis resulted in the identification of 20 compounds representing $96.05 \%$ of the total essential oil which contains $29.39 \%$ monoterpene hydrocarbons, 52.55\% oxygenated monoterpenes, $13.16 \%$ sesquiterpene hydrocarbons and $0.95 \%$ oxygenated sesquiterpenes. Furthermore, the most abundant components (> $4 \%$ ) of the Tunisian Rosmarinus officinalis $L$ essential oil were a-pinene (14.05\%), camphene (6.14\%), camphor (15.32\%), borneol (13.63\%) and geraniol (16.32\%). The identified compounds are known and were reported in previous studies. 
However, the composition of the Tunisian rosemary essential oil is different from other Mediterranean rosemary oils [27, 28]. This could be related to rosemary variety, climatic conditions and period of plant collection.

Table 2 : Chemical composition of Rosmarinus officinalis L. essential oil

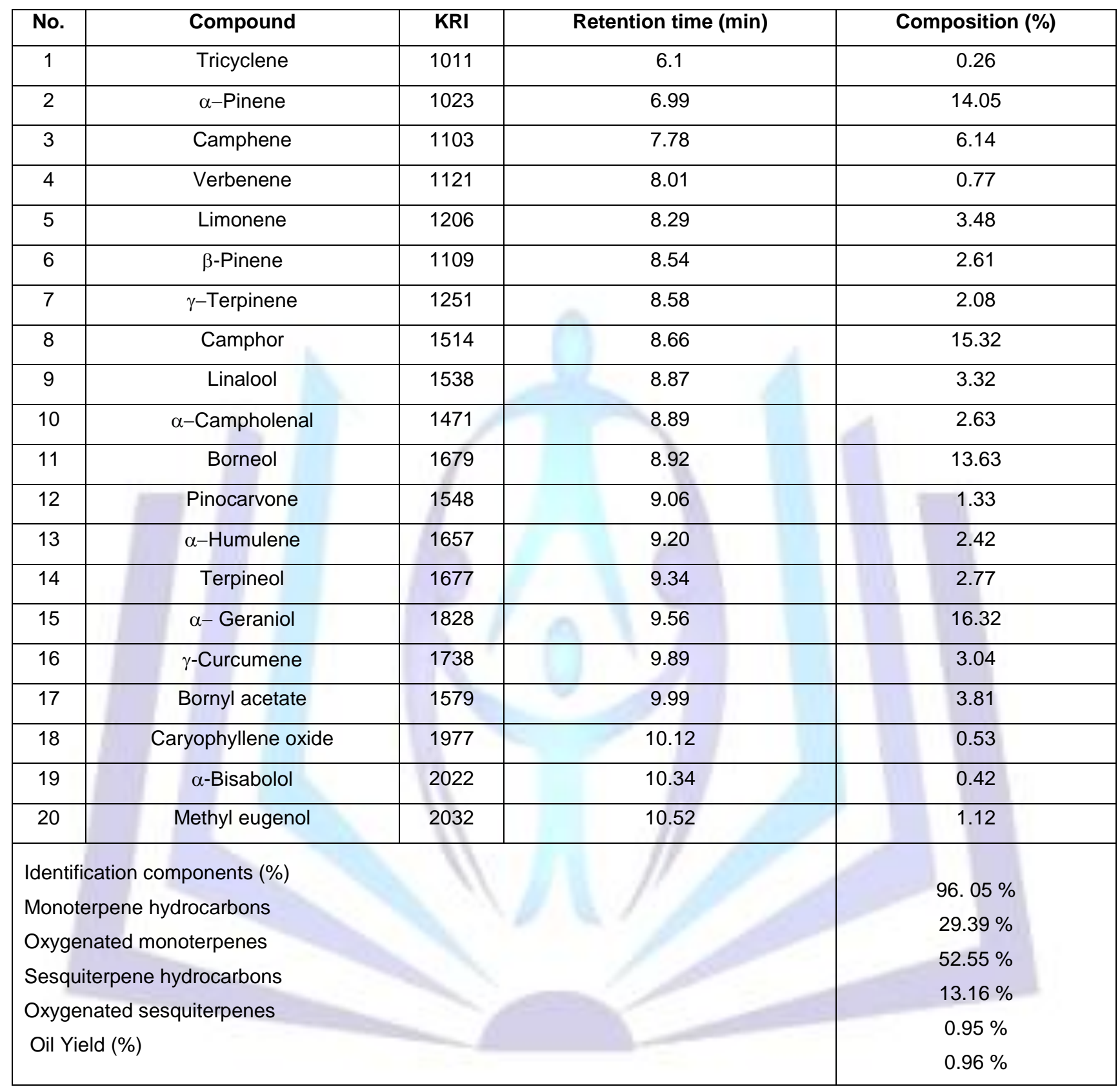

No: Numbers correspond to the peaks observed in the GC-MS chromatogram. KRI: Kovats Retention Index, retention index relative to n-alcane on DB-5MS Capillary column. w/fw: weight/fresh weight.

\section{Polyphenols and flavonoids determination}

polyphenols have received considerable attention because of their physiological function, including antioxidant, antidiabetic, antimutagenic and antitumour activities [29]. Phenolic compounds such as flavonoids, phenolic acids and tannins are widely distributed in plants, which have gained much attention, due to their antioxidant activities and free radical-scavenging abilities, with beneficial implications for human health [30].

Table 3 summarises the results from the quantitative determination of the flavonoids and total phenol contents of the different extracts. Except the essential oil, all extracts were found to be rich in flavonoids and polyphenols. The methanolic extract had high levels of phenolic $(282.98 \pm 5.63 \mu \mathrm{g} \mathrm{GAE} / \mathrm{mg}$ extract) and flavonoid $(161.05 \pm 2.32 \mu \mathrm{g} \mathrm{QE} / \mathrm{mg}$ extract) contents. The ethyl acetate extract contained less amounts of polyphenols (12.69 $\pm 2.51 \mu \mathrm{g} \mathrm{GAE} / \mathrm{mg}$ extract) and flavonoids (72.94 $\pm 4.33 \mu \mathrm{g} \mathrm{QE} / \mathrm{mg}$ extract) than methanolic extract. In a previous study, Erkan et al. [31] have determined the total phenol content of the methanolic extract from Greece rosemary (162 $\mu \mathrm{g} \mathrm{GAE} / \mathrm{mg}$ extract) which was lower than that found in our work. This can be explained by the period and region of plant harvest. 
Table 3 : The contents of total flavonoid and phenolic compounds

\begin{tabular}{|c|c|c|}
\hline Extract & $\begin{array}{c}\text { Total flavonoids }^{\mathrm{a}} \\
(\mu \mathrm{g} \mathrm{QE} / \mathrm{mg} \text { extract })\end{array}$ & $\begin{array}{c}\text { Total phenols }^{\mathrm{D}} \\
(\mu \mathrm{g} \text { GAE} / \mathrm{mg} \text { extract })\end{array}$ \\
\hline Ethyl Acetate extract & $12.69 \pm 4.33$ & $44.69 \pm 2.51$ \\
\hline Methanol extract & $161.05 \pm 2.32$ & $282.98 \pm 5.63$ \\
\hline Essential oil & - & - \\
\hline
\end{tabular}

a: Total flavonoids expressed as quercetin equivalents: micrograms quercetin per milligram (dry weight) extract.

b: Total phenols expressed as gallic acid equivalents: micrograms gallic acid per milligram (dry weight) extract

\section{LC/MS analysis}

Methanol extract of $R$. officinalis leaves extract was subjected to high performance liquid chromatography, coupled to photodiode-array and electrospray ionisation mass spectrometric analysis (LC/DAD/ELSD/ESI-MS ${ }^{n}$ ) in order to obtain a tentative identification of his composition. Eight coumpounds were identified belonging to two representative classes of constituents: flavonoids and phenolic terpens. Three unknown compounds were also detected. Rosmanic acid was the only hydroxycinnamic derivative that was identified (Figure 1).

Because polyphenols contain one or more hydroxyl and/ or carboxylic acids groups, MS data were acquired in a negative ionization mode. The identification was based on chromatographic behaviour, mass spectra obtained under electron spray ionisation (ESI) conditions and comparison with reference compounds and scientific publications For the remaining compounds for which no standards were available, identification was based on accurate mass measurements of the pseudomolecular $[\mathrm{M}-\mathrm{H}]$ ions and their fragmentation pattern, as has been documented in the literature [32]. Table 4 shows the retention times, mass spectrometric characteristics in negative mode as well as the name of the identified compounds.

Coumpound 3 gave a $[\mathrm{M}-\mathrm{H}]$ ion at $\mathrm{m} / \mathrm{z} 305$ attribueted to galocatechin a flavonoid previously reported in rosmary extracts [33]. Compound 6 gave a [M-H] ion at $\mathrm{m} / \mathrm{z} 477$ attributed to isorhamnetin-3-O-hexoside. Its MS/MS data showed the loss of a hexose moiety (162 amu) resulting in the fragment ions at $\mathrm{m} / \mathrm{z} 315$ corresponding to a deprotonated molecular ion of isorhamnetin in agreement with literature data [33]. Likewise, the $\mathrm{MS}_{2}$ experiment for compound 7 with [M-H] at $\mathrm{m} / \mathrm{z} 461$ showed the loss of a hexose moiety confirming the presence of homoplantaginin, which has been previously reported in rosemary and extracts [34, 35]. The last flavonoid identified, compound 8, was the aglycon hispidulin (at $\mathrm{m} / \mathrm{z} 299$ ) eluting at $23,7 \mathrm{~min}$.

The peak with $[\mathrm{M}-\mathrm{H}]$ at $\mathrm{m} / \mathrm{z} 345$, were found, i.e., isomer of rosmanol (compound 9 ). $\mathrm{MS}_{2}$ analysis at $\mathrm{m} / \mathrm{z} 345 \mathrm{gave}$ the $\mathrm{m} / \mathrm{z} 301$, corresponding to the [M-H-CO2] fragments, in agreement with literature data [35, 36].

Coumpounds 10 and 11 are attribueted to carnosic acid and carnosol which were among the most frequently compounds reported in rosmary polar extracts (Herrero, plaza, Cfeuentes, \&lbáñez, 2010).

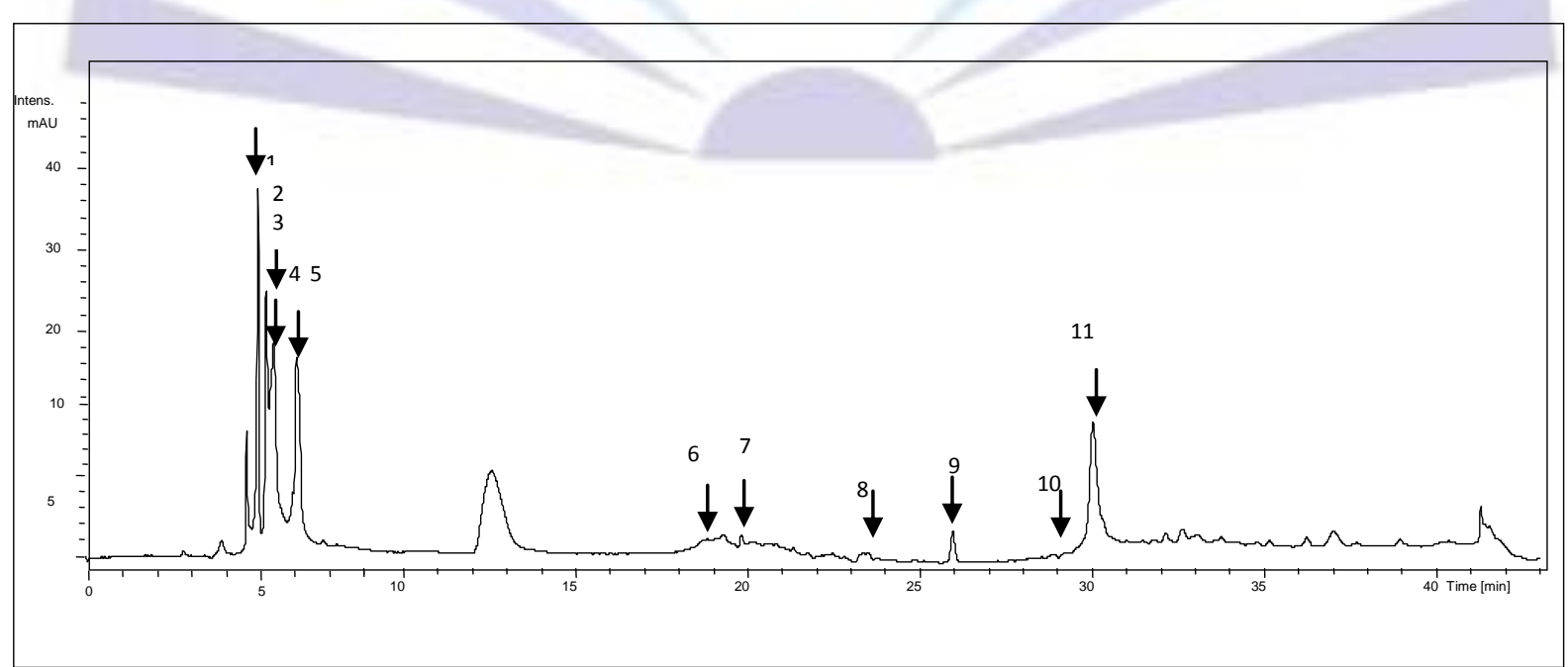

Fig 1: LC/MS chromatogram of R.officinalis leaves MeOH extract ; 1: unkown ; 2: unkown; 3: gallocatechin; 4: Rosmanic acid; 5: unkown; 6: rosmanol isomer; 7: carnosic acid; 8: carnosol; 9: rosmanol isomer ; 10: carnosic acid; 11: carnosol 
Table 4: Peak assignments of $\mathrm{MeOH}$ rosemary leaves extract

\begin{tabular}{|c|c|c|c|c|}
\hline Compounds & Rt (min) & {$[\mathrm{M}-\mathrm{H}]^{-}(\mathrm{m} / \mathrm{z})$} & $-\mathrm{MS}^{2}[\mathrm{M}-\mathrm{H}]^{-}(\mathrm{m} / \mathrm{z})(\%)$ & Compounds \\
\hline 1 & 4,8 & 165 & $144(100)$ & Unknown \\
\hline 2 & 5,2 & 191 & $155(100)$ & Unknown \\
\hline 3 & 5,3 & 305 & $226(100)$ & gallocatechin \\
\hline 4 & 5,7 & 359 & $161(100)$ & Rosmarinic acid \\
\hline 5 & 6,7 & 341 & $281(100)$ & Unknown \\
\hline 6 & 18,6 & 477 & $315(100)$ & Isorhamnetin-3-O-hexoside \\
\hline 7 & 19,5 & 461 & $299(100)$ & Homoplantaginin \\
\hline 8 & 23,7 & 299 & $283(100)$ & Hispidulin \\
\hline 9 & 25,7 & 345 & $301(100)$ & Rosmanol isomer \\
\hline 10 & 29,3 & 331 & $287(100)$ & Carnosic acid \\
\hline 11 & 30 & 329 & $285(100)$ & Carnosol \\
\hline
\end{tabular}

Rt : retention times

a identification confirmed using commercial standards

\section{Alpha-amylase inhibitory assay in vitro}

This assay evaluated the ability of Rosemary extracts to inhibit the activity of a-amylase, a digestive enzyme secreted from the pancreas and salivary gland. Alpha-amylase is involved in important biological processes such as digestion of carbohydrates. Many crude drugs inhibit a-amylase activity [38]. Natural $\alpha$-amylase inhibitors are beneficial in reducing post-prandial hyperglycemia by delaying the digestion of carbohydrates and consequently the absorption of glucose.

Table 5: Alpha-Amylase and Pancreatic Lipase inhibition assays of Rosemary extracts

\begin{tabular}{|c|c|c|c|c|c|}
\hline \multicolumn{2}{|c|}{ Parameters } & \multicolumn{2}{|c|}{$\alpha$-amylase activity } & \multicolumn{2}{|c|}{ Pancreatic lipase activity } \\
\hline Sample & Concentration $(\mu \mathrm{g} / \mathrm{ml})$ & $\%$ inhibition & $I C_{50}(\mu \mathrm{g} / \mathrm{ml})$ & \% inhibition & $I C_{50}(\mu \mathrm{g} / \mathrm{ml})$ \\
\hline \multirow{3}{*}{ Acarbose } & 25 & $84.00 \pm 2.1$ & \multirow{3}{*}{14.88} & & \\
\hline & 50 & $88.72 \pm 2.07$ & & \multirow[t]{2}{*}{ - } & \\
\hline & 100 & $90.35 \pm 1.75$ & & & \\
\hline \multirow{3}{*}{ Fluvastatin } & 25 & \multirow{3}{*}{\multicolumn{2}{|c|}{ - }} & $74.58 \pm 1.13$ & \multirow{3}{*}{16.76} \\
\hline & 50 & & & $86.78 \pm 1.27$ & \\
\hline & 100 & & & $93.35 \pm 1.25$ & \\
\hline \multirow{3}{*}{$\begin{array}{c}\text { Ethyl acetate } \\
\text { extract }\end{array}$} & 50 & $73.31 \pm 1.22$ & \multirow{3}{*}{34.11} & $68.24 \pm 1.34$ & \multirow{3}{*}{36.63} \\
\hline & 100 & $84.01 \pm 1.57$ & & $78.49 \pm 1.62$ & \\
\hline & 200 & $95.55 \pm 1.33$ & & $84.21 \pm 1.75$ & \\
\hline \multirow{3}{*}{$\begin{array}{c}\text { methanolic } \\
\text { extract }\end{array}$} & 50 & $82.25 \pm 1.73$ & \multirow{3}{*}{30.39} & $73.36 \pm 2.07$ & \multirow{3}{*}{34.07} \\
\hline & 100 & $85.55 \pm 1.13$ & & $81.13 \pm 1.69$ & \\
\hline & 200 & $98.68 \pm 1.25$ & & $88.76 \pm 1.97$ & \\
\hline \multirow{3}{*}{ Essential oil } & 50 & $88.13 \pm 1.37$ & \multirow{3}{*}{28.36} & $77.53 \pm 1.57$ & \multirow{3}{*}{32.25} \\
\hline & 100 & $96.65 \pm 1.07$ & & $83.77 \pm 1.83$ & \\
\hline & 200 & $98.33 \pm 1.43$ & & $91.02 \pm 2.13$ & \\
\hline
\end{tabular}

The data are expressed in mean \pm S.E.M. $n=3$ in each group. 
Table 5 indicated that each extract from Rosemary showed a potent inhibition of $\alpha$-amylase enzyme. The $\mathrm{IC}_{50}$ values of Rosemary essential oil, ethyl acetate and methanolic extracts against $\alpha$-amylase were 28.36, 34.11 and $30.39 \mu \mathrm{g} / \mathrm{ml}$ respectively. Moreover, $\alpha$-amylase activity underwent a strong inhibition via Acarbose $\left(\mathrm{IC}_{50}=14.88 \mu \mathrm{g} / \mathrm{ml}\right)$. It should be mentioned that Acarbose has been used for management of post-prandial hyperglycemia but it was reported that this agent was associated with several health side effects [27].

The potent a-amylase inhibitory activity of Rosmary ethyl acetate and methanolic extracts depended on their total phenolics and flavonoids contents. In fact, many phenolic compounds and specially flavonoids have been reported as potential antidiabetic agents because they exert a good inhibiting action of $\alpha$-amylase and could have potential prevention in diabetes mellitus as part of a dietary strategy [28, 29]. Furthermore, the terpenes such as $\beta$-pinene which exist in rosemary essential oil might inhibited key enzymes related to type 2 diabetes principally $\alpha$-amylase. It was reported that administration of terpenenes to diabetic exerts blood glucose lowering effect and high antioxidant activity in alloxaninduced diabetic rat [30].

\section{Inhibitory activity of Rosemary extracts against pancreatic lipase}

Pancreatic lipase is the most important enzyme responsible for the digestion of dietary triglycerides in which it hydrolyzes non-absorbable triglycerides into absorbable glycerol and fatty acids by small intestine [4], inhibition of this digestive enzyme is therefore beneficial in the treatment of obesity [31].

As shown in table 5, all the evaluated extracts interestingly suppressed the activity of pancreatic lipase. Thus the $\mathrm{IC}_{50}$ of essential oil, ethyl acetate and methanolic extracts against lipase activity were $32.25,36.64$ and $34.07 \mu \mathrm{g} / \mathrm{ml}$, respectively, which indicated that Rosemary is endowed with a strong anti-obesity effect. It should be noted that fluvastatin, an antihyperlipidemic agent [32], showed more potent inhibition of pancreatic lipase $\left(\mathrm{IC}_{50}=16.76 \mu \mathrm{g} / \mathrm{ml}\right)$ than the other evaluated extracts. Moreover, the inhibitive capacities of the different fractions against the lipase might perfectly coincident with their total phenolics compounds. It was reported that the inhibitory lipase activity might be derive from the phenolic compounds found in some medicinal plants such as gallic acid, catechin, epicatechin, ellagic acid, myricetin, quercetin, kaempferol, resveratrol, and anthocyanins [44,45].

\section{Thermal stability of rosemary methanolic extracts}

Fig. 2 shows the Effect of heating on methanolic extract from rosemary (at $185^{\circ} \mathrm{C}$ ) for different intervals. antioxidant activity using DPPH radical scavenging method was employed for the Evaluation of thermally treated extract stability.

During 50 min heating time, Extract was almost stable. But a slight gradual decrease in antioxidant activity (increase in $\mathrm{IC}_{50}$ values) was observed around $55 \mathrm{~min}$. The decrease in antioxidant activity become pronounced after 80 min heating time. extract lost considerably its antioxidant activity which becomes much weaker than BHT after 120 min heating time. this result is more interessant than that reported in our previous study using basil [14].

This loss of antioxidant activity can be explained by various chemical reactions leading to the formation of hydroperoxides, hydrolysis, polymerization and chemical decomposition after longer heating times at high temperatures, which lead to deterioration in oils and fats giving rancidity [46]. These results reveal rosemary to be a potential source of natural antioxidants, applicable in food systems even at high processing temperatures. In fact, Rosemary (Rosmarinus officinalis $L$.) is a rich source of di-and triterpenoids, phenolic acids, and flavonoids, especially Carnosic acid, carnosol and rosmarinic acid wchich are the main antioxidant compounds [32].

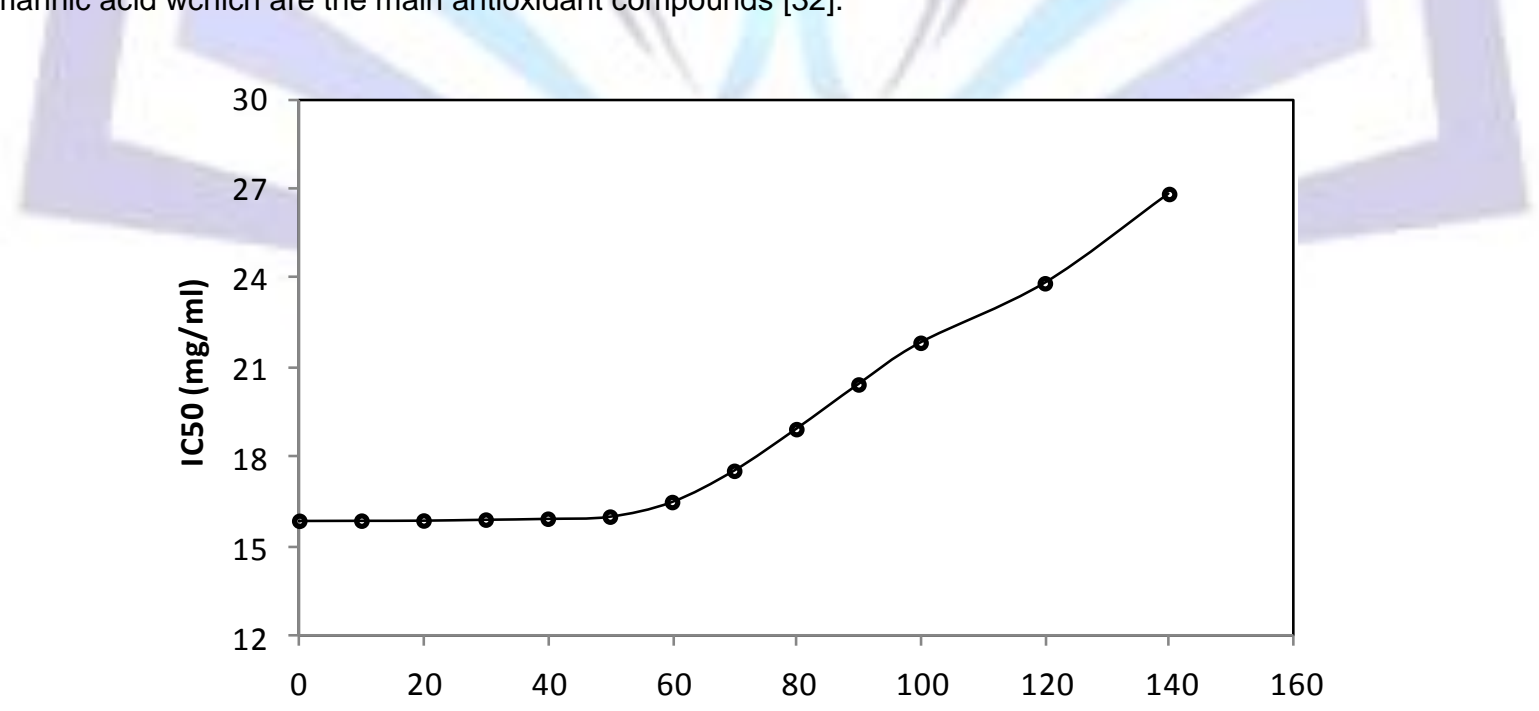

Heating Time (h)

Fig 2: Antioxidant activity of thermally treated methanolic extracts of rosemary 


\section{Determination of induction period (IP) to primary oil oxidation with Rancimat method}

Induction period (IP) provides direct evidence for trends in resistance to oxidative rancidity of vegetable oils. IPs were determined in all cases at $100^{\circ} \mathrm{C}$ measured by Rancimat. The SFO oxidative resistance was greatly improved in the presence of rosemary methanolic extracts (Table 6). Indeed, the induction time of SFO increased significantly from 2.05 (control) to $3.52,9.12$ and $12.93 \mathrm{~h}$ by enrichment with 200,500 and $1000 \mathrm{ppm}$ of rosemary methanolic extract, respectively. Rosemary methanolic extract at $500 \mathrm{ppm}$ was significantly more effective $(9,12 \mathrm{~h})$ than $\mathrm{BHT}$ at $200 \mathrm{ppm}$ $(4.72 \mathrm{~h})$ or $500 \mathrm{ppm}$ methanolic extract of garlic $(2.79 \mathrm{~h})$ methanolic extract of pomegranate peel $(4.07 \mathrm{~h})$ or basil $(8,23 \mathrm{~h})$ $[47,48,14]$. The highest stability of SFO supplemented with rosemary methanolic extract can be explained by its richness in components with powerful antioxidant activity, such as carnosic acid, carnosol, rosmarinic acid, rosmanol, epirosmanol, methyl carnosate, isorosmanol, 7-methylepirosmanol, rosmaridiphenol and rosmariquinone [15, 49, 50].

Table 6 : Antioxidant effects on sunflower oil measured by Rancimat under $100{ }^{\circ} \mathrm{C}$.

\begin{tabular}{|c|c|c|}
\hline Sample & Concentration (ppm) & Induction period (h) \\
\hline Ctrl & 0 & $4.05 \pm 0.05$ \\
\hline SFO + BHT & 200 & 3.04 \\
\hline SFO + RME & 200 & 0.01 \\
\hline SFO + RME & 500 & $9.12 \pm 0.03$ \\
\hline SFO + RME & 1000 & $12.93 \pm 0.04$ \\
\hline
\end{tabular}

Ctrl: control; SFO: sunflower oil; RME: rosemary methanolic extract. Data are mean $(n=3) \pm$ standard deviation $(n=3)$, $(p$ $<0.05)$.

\section{Weight gain (WG)}

Weight gain (WG) is a technique generally employed for quantitative assessment of the amount of oxygen added to the unsaturated content of lipid molecules and formation of hydroperoxides during oxidation. This amount of oxygen is used as a good parameter for determining the induction period besides extent of oxidation and effect of antioxidants on the stability of oils. When there is no oxidation, oil samples weight remains practically constant. WG was measured for all the stabilized and control samples after $24 \mathrm{~h}$ intervals up to 16 days and results were calculated in percentage (Fig.3). Initially, WG was not appreciable but it increased very sharply for all the samples reaching a maximum value followed by a sharp decrease, after some time at maximum value, during the last days of storage. A significant increase in induction period of all the stabilized samples was observed compared to the control. Indeed, the time taken to achieve $0.5 \%$ increase in weight was 3.26, 4.28, 5.41, 8.1 and 11.2 days for Ctrl, SFO-200, SFO-BHT, SFO-500, and SFO-1000, respectively (Fig.2). These results show that the synthetic antioxidant, BHT has induction time between SFO-200 and SFO-500. It may be roughly that rosemary and basil methanolic extract at $300-400$ ppm has the same effect as BHT at 200 ppm in SFO stabilisation.

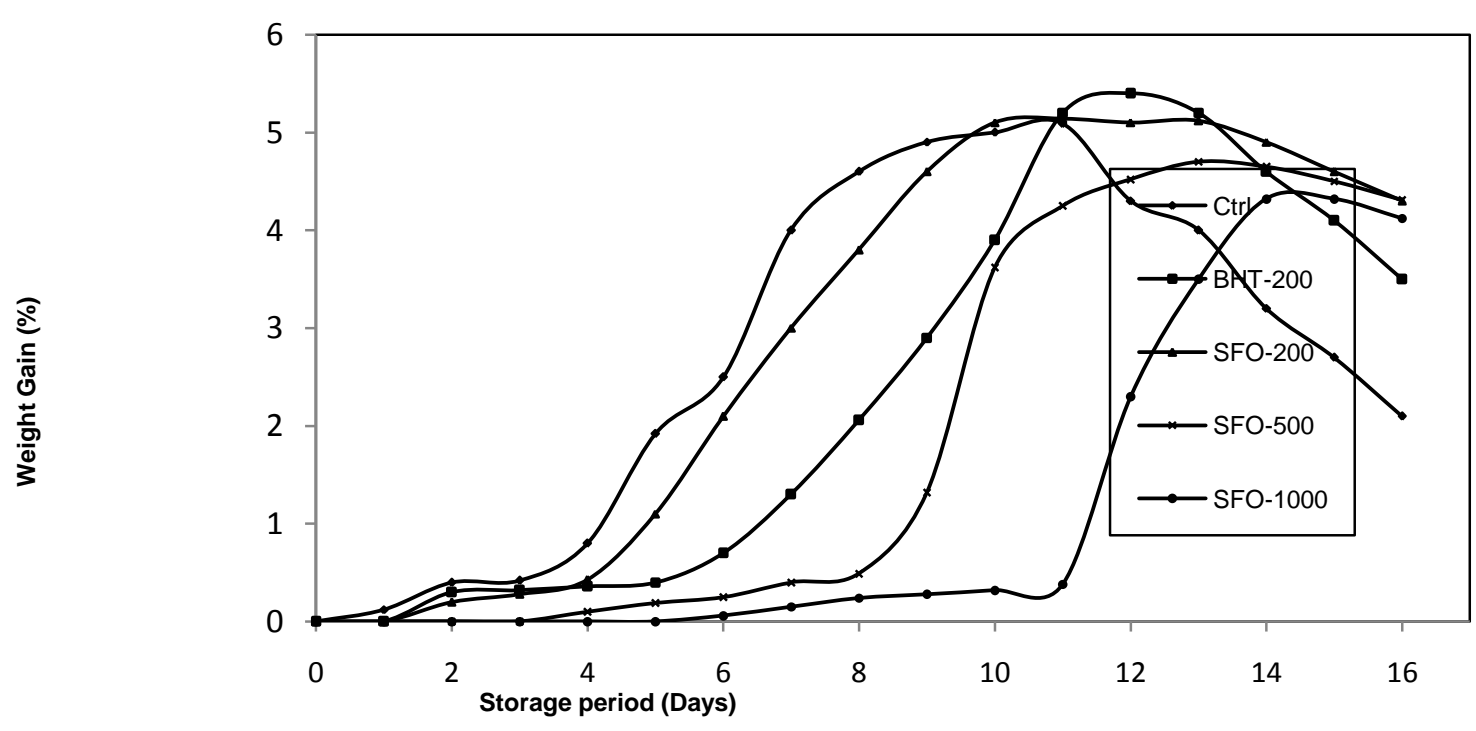

Fig 3: Increase in weight gain (WG) of control and stabilized sunflower oil samples with rosmary methanolic extract under accelerated storage 


\section{CONCLUSION}

The results obtained in this study demonstrated for the first time that rosemary is a potent source of natural inhibitors of $\alpha$ amylase and pancreatic lipase with powerful antioxidants proprieties that might be used in the food stabilization and the prevention of diabetes and obesity complications to be explored for new complementary pharmacological drug.

\section{ACKNOWLEDGMENTS}

This research was supported by the Laboratory of Natural Products Chemistry in Faculty of Sciences of Sfax in Faculty of Sciences of Sfax (Tunisia) and the Center of Biotechnology of Sfax(Tunisia) .

\section{REFERENCES}

[1] Leena, A.A., and Jill, P.C. 2010. Type 2 Diabetes Prevention: A Review. Clinical Diabetes. 28, 53-59.

[2] Shobana S, Sreerama Y.N, Malleshi N.G. 2009. Composition and enzyme inhibitory properties of finger millet (Eleusine coracana L.) seed coat phenolics: mode of inhibition of a-glucosidase and pancreatic amylase. Food Chem. 115:1268-1273.

[3] Hamden, K., Keskes, H., Belhaj, S., and et al. 2011. Inhibitory potential of omega-3 fatty and fenugreek essential oil on key enzymes of carbohydrate-digestion and hypertension in diabetes rats. Lipids Health Dis. 10, 226.

[4] Rahul,.B., Biraria, R.B., and Bhutani, K.K. 2007. Pancreatic lipase inhibitors from natural sources: unexplored potential Drug Discov. Today. 1219, 879-889.

[5] Martins, F., Noso, M.T., Porto, V.B. and et al. 2009. Maté Tea Inhibits in Vitro Pancreatic Lipase activity and Has Hypolipidemic Effect on High-fat Diet-induced Obese Mice. Obesity. 18, 42-47.

[6] Vijayakumar, M., Govindarajan, R., Rao, G.M.M., and et al. 2006. Action of Hygrohila auriculata against streptozotocin-induced oxidative stress. J. Ethnopharmacol. 104, 356-361.

[7] Che Man, Y.B., and Tan, C.P. 1999. Effects of natural and synthetic antioxidants on changes in refined, bleached, and deodorized palm olein during deep-fat frying of potato chips. J. Am. Oil Chem. Soc. 76,331-339.

[8] Addis, P.B., and Warner, G.J. 1991. The potential aspects of lipid oxidation products in food. In: O. I. Aruoma \& B. Halliwel (Eds) Free radicals and food additives, Taylor Francis Ltd, London.

[9] Barlow, S.N. 1990. Toxicological aspects of antioxidants used as food additives. In B. J. F. Hudson (Ed.), Food antioxidants, Elsevier, Amsterdam, 253-307.

[10] Hamden, K., Allouche, N., Damak, M., and Elfeki, A. 2009. Hypoglycemic and antioxidant effects of phenolic extracts and purified hydroxytyrosol from olive mill waste in vitro and in rats. Chem. Biol. Interact. 180. 421-432.

[11] Dawidowicz, A.L., Wianowska, D., Baraniak, B. 2006. The antioxidant properties of alcoholic extracts from Sambucus nigra L. (antioxidant properties of extracts). Food Sci. Technol-Leb. 39, 308-315.

[12] Allouche, N., Fki, I., and Sayadi, S. 2004. Toward a high yield recovery of antioxidants and purified hydroxytyrosol from olive mill wastewaters. J. Agric. Food Chem. 52, 267-273.

[13] Fki, I., Allouche, N., and Sayadi, S. 2005. The Use of Polyphenolic Extract, Purified Hydroxytyrosol and 3, 4Dihydroxyphenyl Acetic Acid From Olive Mill Wastewater for the Stabilization of Refined Oils: a Potential Alternative to Synthetic Antioxidants. Food Chem. 93, 197-204.

[14] Ben Ali, M., Dhouib, K., Damak, M and Allouche, N. 2014. Stabilization of Sunflower Oil During Accelerated Storage: Use of Basil Extract as potential Alternative to Synthetic Antioxidants.17, 1547-1559.

[15] Peng, Y., Yuan, J., Liu, F., and Ye, J. 2005. Determination of active components in rosemary by capillary electrophoresis with electrochemical detection. J. Pharmaceut. Biomed. 39, 431-437.

[16] Haloui , M., Louedec, L., Michel, J.B., and Lyoussi, B., 2000. Experimental diuretic effects of Rosmarinus officinalis and Centaurium erythraea. J.Ethnopharmacol. 71, 465-472.

[17] Arslan, D., Musa, Özcan, M., 2008. Evaluation of drying methods with respect to drying kinetics, mineral content and colour characteristics of rosemary leaves. Energ. Convers. Manage. 49, 1258-1264.

[18] Shahidi, F., Janitha, P.K., Wanasundara, P.D. 1992. Phenolic antioxidants. Crc. Cr. Rev. Food Sci. 32, 67-103.

[19] Lamaison, J.L., and Carnat, A. 1990. Teneurs en acide rosmarinique, en dérivés hydroxycinnamiques totaux et activités antioxydantes chez les Apiacées, les Borraginacées et les Lamiacées médicinales. Pharm. Acta. Helv. $65,315-320$

[20] Khadri, A., Neffati, M., Smiti, S., Falé, P., and et al (2010). Antioxidant, antiacetylcholinesterase and antimicrobial activities of Cymbopogon schoenanthus L. Spreng (lemon grass) from Tunisia. Lebensm. Wiss. Technol. 43, 331336. 
[21] Oktay, M., Gulcin, I., Kufrevioglu, O.I. 2003. Determination of in vitro antioxidant activity of fennel (Foeniculum vulgare) seed extracts. Lebensm. Wiss. Technol. 36, 263-271.

[22] Gella, F.J., Gubern, G., Vidal, R., and Canalia, F. 1997. Determination of total and pancreatic $\alpha$-amylase in human serum with 2-chloro-4- nitrophenyl-a-D-maltotrioside as substrate. Clinica Chimica Acta. 259, 147-160.

[23] Nakai, M., Fukui, Y., Asami, S., and et al. 2005. Inhibitory effects of oolong tea polyphenols on pancreatic lipase in vitro. J.Agr. Food Chem. 53, 4593-4598.

[24] Adams, R.P. 2001. Quadrupole Mass Spectra of Compounds Listed in Order of Their Retention Time on DB-5. Identification of Essential Oils Components by Gas Chromatography/Quadrupole Mass Spectroscopy. Allured Publishing Corporation, Carol. Stream, IL, USA, 456.

[25] Davies, N.W. 1990. Gas chromatographic retention indices of monoterpenes on methyl silicone and Carbowax $20 \mathrm{M}$ phases. J.Chromatogr. 503, 1-24.

[26] Duh, P.D., and Yen, G.C. 1997. Antioxidant efficacy of methanolic extracts of peanut hulls in soybean and peanut oils. J. Am. Oil Chem. Soc. 74, 745-748.

[27] Laborda, R., Manzano, I., Gamón, M., and et al. 2013. Effects of Rosmarinus officinalis and Salvia officinalis essential oils on Tetranychus urticae Koch (Acari: Tetranychidae). Ind. Crop. Prod. 48, 106-110.

[28] Orhan, I., Aslan, S., Kartal, M., and et al. 2008. Inhibitory effect of Turkish Rosmarinus officinalis L.on acetylcholinesterase and butyrylcholinesterase enzymes. Food Chem. 108, 663-668.

[29] Othman, A., Ismail, A., Ghani, N.A., Adenan, I. 2007. Antioxidant capacity and phenolic content of cocoa beans. Food Chem. 100, 1523-1530.

[30] Govindarajan, R., Singh, D.P., and Rawat, A.K.S. 2007. High-performance liquid chromatographic method for the quantification of phenolics in 'Chyavanprash' a potent Ayurvedic drug. J. Pharm. Biomed. Anal. 43, 527-532.

[31] Erkan, N., Ayranci, G., and Ayranci, E. 2008. Antioxidant activities of rosemary (Rosmarinus Officinalis L.) extract, blackseed (Nigella sativa L.) essential oil, carnosic acid, rosmarinic acid and sesamol. Food Chem. 110, 76-82.

[32] Cuvelier, M., Berset, C., and Richard, H. 1994. Antioxidant constituents in sage (Salvia officinalis). J. Agr. Food Chem. 42, 665-669.

[33] Hossain, M.B., Rai, D.K., Brunton, N.P., and et al. 2010. Characterization of phenolic composition in lamiaceae spices by LC-ESIMS/MS J.Agr. Food Chem. 58, 10576-10581.

[34] Borrás Linares, I., Arráez-Román, D., Herrero, M., and et al. 2011. Comparison of different extraction procedures for the comprehensive characterization of bioactive phenolic compounds in Rosmarinus officinalis by reversedphase high-performance liquid chromatography with diode array detection coupled to electrospray time-offlight mass spectrometry. J. Chromatogr. A. 1218, 7682-7690.

[35] Cuvelier, M. E., Richard, H., and Berset, C. 1996. Antioxidative activity and phenolic composition of pilot-plant and commercial extracts of sage and rosemary. J. Am. Oil Chem. Soc. 73, 645-652.

[36] Zimmermann, B. F., Walch, S. G., Tinzoh, L. N., and Stühlinger, W. 2011. Rapid UHPLC determination of polyphenols in aqueous infusions of Salvia officinalis L. (sage tea). J.Chromatogr.B. Analytical Technologies in the Biomedical and Life Sciences. 879, 2459-2464.

[37] Herrero, M., Plaza, M., Cifuentes, A., and Ibáñez, E. 2010. Green processes for the extraction of bioactives from rosemary: chemical and functional characterization via ultra-performance liquid chromatography-tandem mass spectrometry and in-vitro assays. J.Chromatogr.A. 1217, 2512-2520.

[38] Kobayashi, K., Saito, Y., Nakazawa, I., and Yoshizaki, F. 2000. Screening of crude drugs for influence on amylase activity and postprandial blood glucose in mouse plasma. Biol. Pharm. Bull. 23, 1250-1253.

[39] Madar, Z. 1989. The effect of acarbose and miglitol (bay-m-1099) on postprandial glucose levels following ingestion of various sources of starch by nondiabetic and streptozotocin-induced diabetic rats. J. Nutr. 119, 20232029.

[40] Cazarolli, L.H., Zanatta, L., Alberton, E.H., and et al. 2008. Flavonoids: Prospective drug candidates. Mini Rev. Med. Chem. 8, 1429-1440.

[41] Strømgaard, K., and Nakanishi, K., 2004. Chemistry and biology of terpene trilactones from Ginkgo biloba. Angewandte Chemie. Int. International Edition in English. 19, 1640-1658.

[42] Ono, Y., Hattori, E., Fukaya, Y., and et al. 2006. Anti-obesity effect of Nelumbo nucifera leaves extract in mice and rats. J.Ethnopharmacol. 106, 238-244.

[43] Hussein, O., Shneider, J., Rosenblat, M., and Aviram, M. 2002. Valsartan therapy has additive anti-oxidative effect to that of fluvastatin therapy against low-density lipoprotein oxidation: studies in hyperchole sterolemic and hypertensive patients. J. Cardiovasc. Pharmacol. 40, 28-34. 
[44] Nakai, M., Fukui, Y., Asami, S., and et al. 2005. Inhibitory effects of oolong tea polyphenols on pancreatic lipase in vitro. J. Agr. Food Chem. 53, 4593-459.

[45] McDougall, G.J., Kulkarni, N.N., and Stewart, D. 2009. Berry polyphenols inhibit pancreatic lipase activity in vitro. Food Chem. 115, 193-199.

[46] Warner, K., and Knowlton, S. 1997. Frying quality and oxidative stability of high-oleic corn oils. J. Am. Oil Chem. Soc. 74, 1317-1322.

[47] Iqbal, S., and Bhanger, M.I. 2007. Stabilization of sunflower oil by garlic extract during accelerated storage. Food Chem. 100, 246-254.

[48] Iqbal, S., Haleem, S., Akhtar, M., Zia-ul-Haq, M., and Akbar, J. 2008. Efficiency of pomegranate peel extracts in stabilization of sunflower oil under accelerated conditions. Food Res. Int. 41, 194-200.

[49] Sáenz-López, R., Fernández-Zurbano, P., and Tena, M.T. 2002. Capillary electrophoretic separation of phenolic dieterpenes from rosemary. J. Chromatogr.A. 953, 156-251.

[50] Stefanovits-Banyai, E., Tulok, M.H., Hegedüs, A., Renner, C., and Varga, I.S. 2003. Antioxidant effect of various rosemary (Rosmarinus officinalis L.) clones. Act. Biol. Szeg. 47, 111-113. 